CONF-930537--117

F

SSCL-Preprint-471

May 1993

Distribution Category: 400

M. Green

R. Sponsel

Industrial Harmonic Analysis System for Magnetic Measurements of SSC Collider Arc and High Energy Booster Corrector Magnets

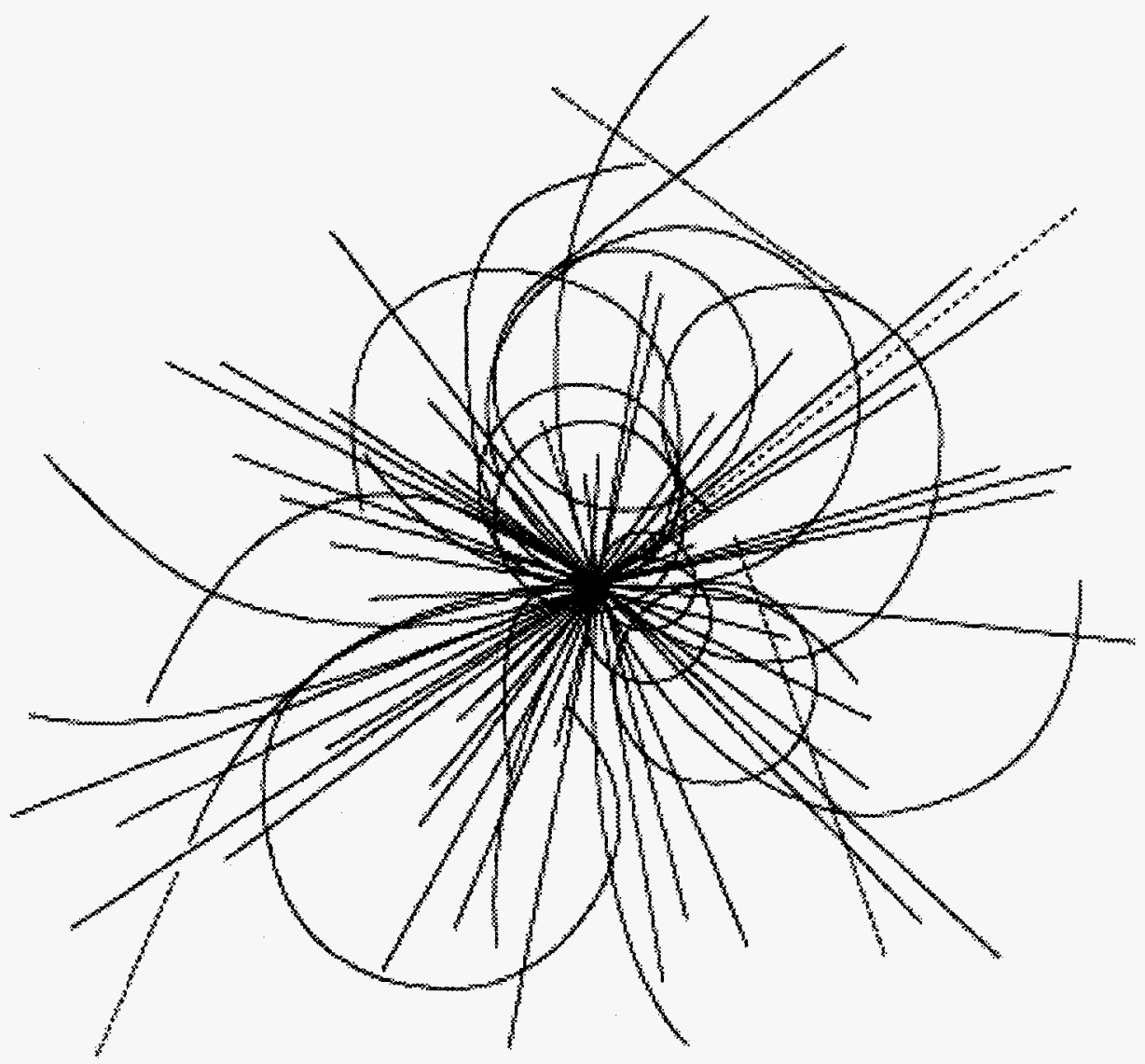

Superconducting Super Collider Laboratory

APPROVED FOR RELEASE OR MUTION - O.R. PATENT GROUP BY...6. $\because D A T E$ \& $2 \%$ \% 


\section{Disclaimer Notice}

This report was prepared as an account of work sponsored by an agency of the United States Government. Neither the United States Government or any agency thereof, nor any of their employees, makes any warranty, express or implied, or assumes any legai liability or responsibility for the accuracy, completeness, or usefulness of any information, apparatus, product, or process disciosed, or represents that its use would not intringe privately owned rights. Feference herein to any specific commercial product, process, or service by trade name, trademark, manufacturer, or otherwise, does not necessarily constitute or imply its endorsement, recommendation, or favoring by the United States Government or any agency thereot. The views and opinions of authors expressed herein do not necessarily state or reflect those of the United States Govemment or any agency thereot.

Superconducting Super Collider Laboratory is an equal opportunity employer. 


\section{DISCLAIMER}

Portions of this document may be illegible in electronic image products. Images are produced from the best available original document. 


\title{
Industrial Harmonic Analysis System for Magnetic Measurements of SSC Collider Arc and High Energy Booster Corrector Magnets*
}

\author{
M. Green, R. Sponsel, and C. Sylvester \\ Superconducting Super Collider Laboratory ${ }^{\dagger}$ \\ 2550 Beckleymeade Ave. \\ Dallas, TX 75237
}

May 1993

${ }^{*}$ Presented at the Fifth Annual International Symposium on the Super Collider, May 6-8, 1993 San Francisco, CA. † Operated by the Universities Research Association, Inc., for the U.S. Department of Energy under Contract No. DE-AC35-89ER40486. 


\title{
INDUSTRIAL HARMONIC ANALYSIS SYSTEM FOR MAGNETIC MEASUREMENTS OF SSC COLLIDER ARC AND HIGH ENERGY BOOSTER CORRECTOR MAGNETS
}

\author{
M. I. Green, R. Sponsel, and C. Sylvester \\ Superconducting Super Collider Laboratory* \\ 2550 Beckleymeade Ave. \\ Dallas, TX 75237-3997
}

\section{INTRODUCTION}

The SSCL collider arc and high energy booster corrector magnets are $50 \mathrm{~mm}$ bore cryogenic magnets. The integral strength and harmonics will be measured by industry at full current at $4.2 \mathrm{~K}$ and at plus and minus $400 \mathrm{~mA}$ at room temperature. Dipoles, quadrupoles, and sextupoles have error tolerances of a few tens of units. A prototype harmonic analysis system for magnetic measurements of production and prototype dipole, quadrupole and sextupole magnets has been designed and is being fabricated. We describe the criteria for search coil designs, data acquisition system hardware and software. Radial search coil arrays are being fabricated utilizing multifilar ${ }^{1}$ wire. Two digital integrators will allow simultaneous accumulation of unbucked and bucked configurations.

\section{DESCRIPTION OF MAGNET MEASUREMENT REQUIREMENTS}

Field strength and harmonics of dipole, quadrupole, sextupole, octupole and decapole corrector magnets need to measured. The bore is $50 \mathrm{~mm}$ and magnet lengths vary from about 0.2 to 1.6 meters. The required field quality of the error harmonics is 10 to 30 units. A unit is defined as $10^{-4}$ of the fundamental field evaluated at a reference radius of $1 \mathrm{~cm}$. The system resolution will be better than 1 unit.

\section{INSTRUMENTATION}

Figure 1 is a block diagram of the instrumentation. The voltage from rotating radial coil arrays is fed to digital integrators which are latched by an incremental optical encoder. Using integrators rather than reading the voltage directly eliminates the need to correct the coil voltages for rotational speed variations.

\footnotetext{
* Operated by the Universities Research Association, Inc., for the U. S. Department of Energy under Contract No. DE-AC35-89ER40486.
} 
Measurements of the error harmonics will be facilitated by utilizing analog bucking, i.e., connecting coils in series opposing to cancel out the fundamental, and one lower harmonic. As the digital integrators have a high input impedance, the system will be able to simultaneously obtain data from the fundamental coil by itself and the fundamental coil output bucked by the output of the compensating coils.

The data acquisition instrumentation is VME based. A Motorola MVME-167 will control the VME bus. The digital integrators are Metrolab 2 PDI 5035 VME bus models which are based upon a voltage-to-frequency converter developed at CERN.

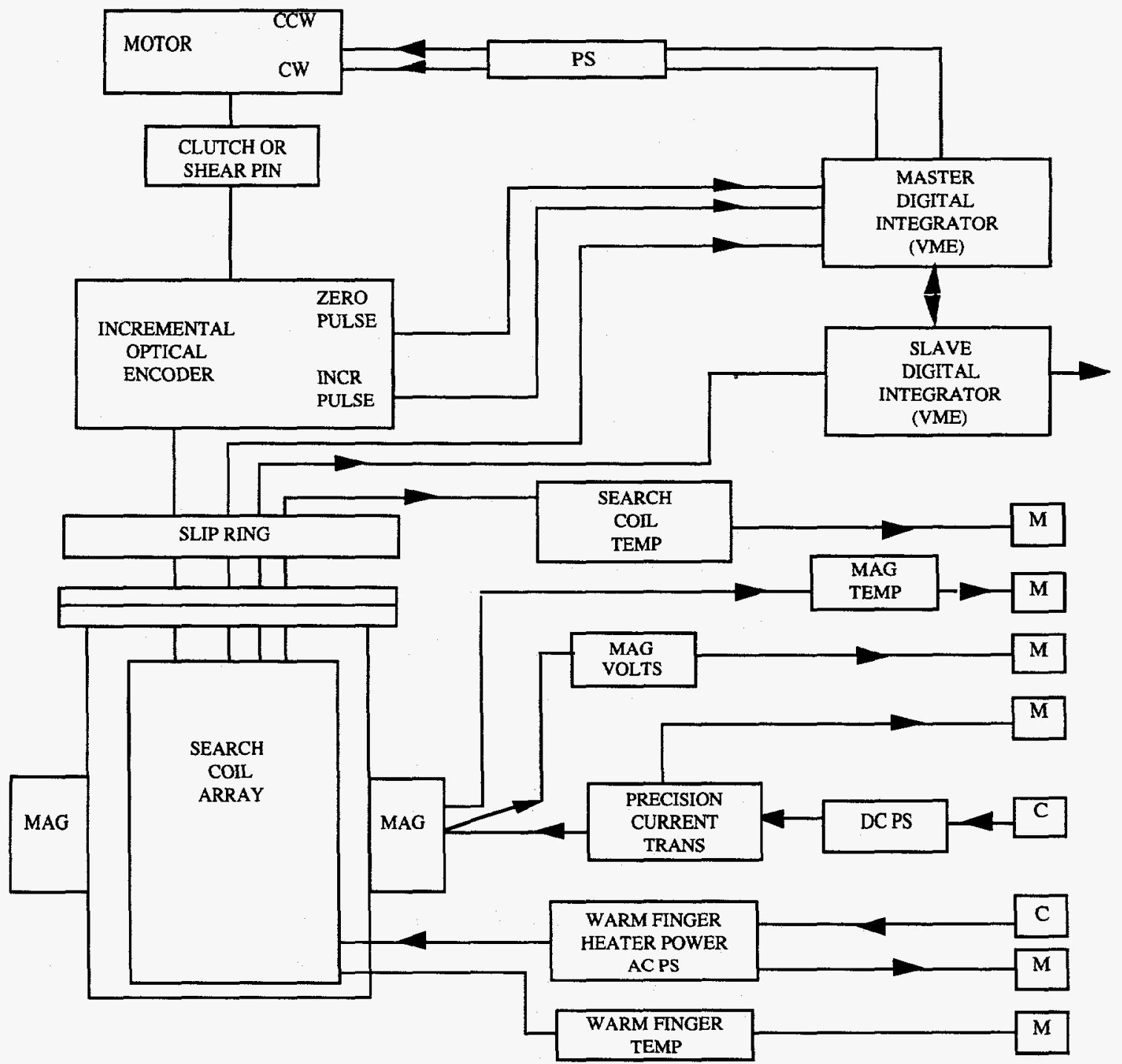

Figure 1. Instrumentation Block Diagram.

\section{SOFTWARE}

Figure 2 is a global structure chart of the software. The operating system will be UNIX based. At the time this publication is being written, we are re-evaluating the computer system architecture and the real time kernel. The initialize \& test hardware module for example, will open, control, monitor and log windows and the log file. It will also check whether the VME crate is on line and whether the instrumentation required for the test is powered and initialized. 


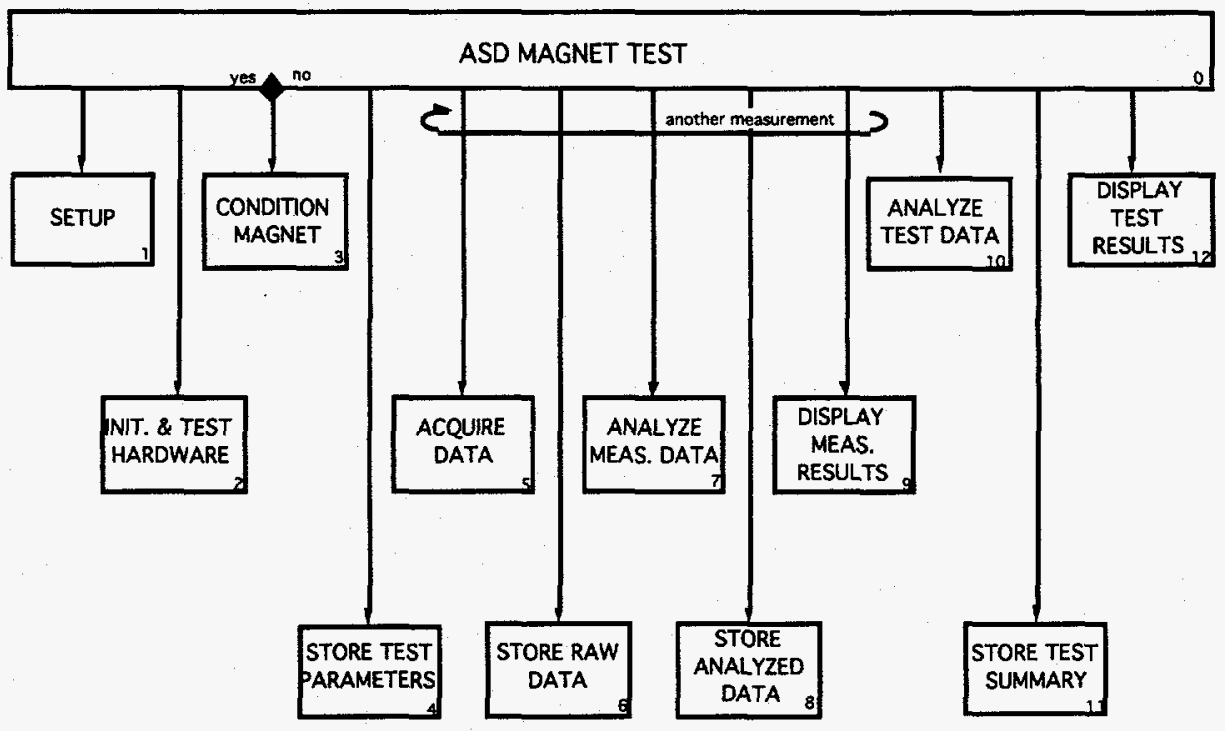

Figure 2. Global structure chart of software.

\section{ELECTRONIC DESIGN OF SEARCH COIL ARRAYS}

A Lotus 123 spreadsheet has been developed for designing search coil arrays for dipoles, quadrupoles and sextupoles. One enters the outside diameter of the rotating coil array, some wire dimensions, a few magnet parameters, and the spread sheet calculates the dimensions of the coil forms, the sensitivity of the search coil array to the fundamental and harmonics and also the expected signal to noise ratio.

The coils must satisfy $\sum p_{i} N_{i} r_{i}^{n}=0$ where $p_{i}$ is the parity of the coil bundle $(+1$ or -1$), N_{i}$ is the number of turns in each coil bundle, and $r_{i}$ is the mean location of the coil bundle, and $n$ is the harmonic number that is being bucked. We are using the notation that $n=1$ indicates the dipole harmonic. For dipole search coil arrays, only one equation needs to be satisfied. For quadrupole search coil arrays, two equations, $n=1$, and $n=2$ must be satisfied.

\section{COIL FORMS}

The dipole search coil array consists of three coplanar "identical" coils that extend completely through the magnet with sufficient length to include end effects. Figure 3 depicts the three identical coil forms. The fundamental coil is on the right, the bucking coil is in the center, and the coil on the left is a dummy coil for mechanical symmetry. The axis of revolution passes through the center of the center coil.

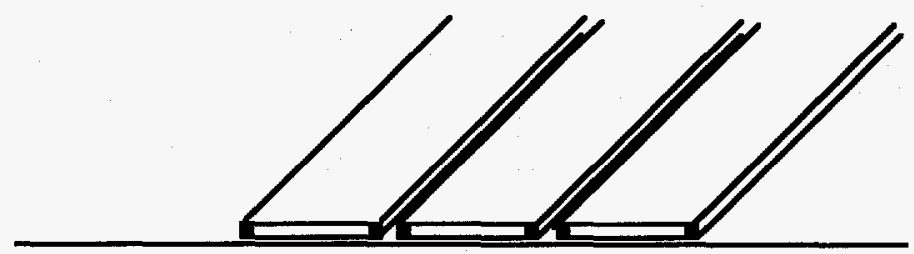

Figure 3. Cross section of dipole search coil array.

The quadrupole search coil array consists of five "identical" radial coils.

\section{COIL FABRICATION}

The coils are wound around a flat Nema G-10 mandrel which has been machined to the required width, thickness, and flatness. 
In the coil winding operation, the mandrel is supported between two flat plates. The multifilar wire is then wound around the mandrel, one layer at a time, with each layer bonded to the previous layer. Completed coils are then calibrated and attached to the support structure. The specified number of coils for a particular assembly, are supported on a Nema G-10 rod and are aligned with the use of two alignment pins, located on the semicircular support rod. A matching semicircular cover, also machined from Nema G-10, is then fastened to the winding support rod to complete this assembly, after the electrical connection for the signal leads have been made.

\section{COIL SUPPORT STRUCTURE}

The coils on the support structure, together with bearings and drive shaft are housed in a brass support tube, which in turn is supported inside a warm finger during use for cold magnetic measurements. The warm finger assembly is being fabricated using type 316-L seamless stainless steel tubing. A heater is installed in the annular space between these two tubes to facilitate vacuum conditioning.

\section{STATUS}

The mechanical design of the system is completed and many of the fabricated components are on hand at SSCL. The majority of the purchased electro-mechanical components such as the optical encoder, stepper motor, slip rings etc., are also on hand. Coil winding is ongoing at SSCL and it is expected that the five coils which are required for the quadrupole system will be completed in approximately two weeks. The instrumentation has been specified and the majority of the components are on hand. The Data Acquisition System software is being designed. Figure 4 shows the coil assembly for the prototype system. Except for the slip ring assembly, this is the drive system design which will be delivered to industrial magnet manufacturers, for measurement of SSCL superconducting corrector magnets.

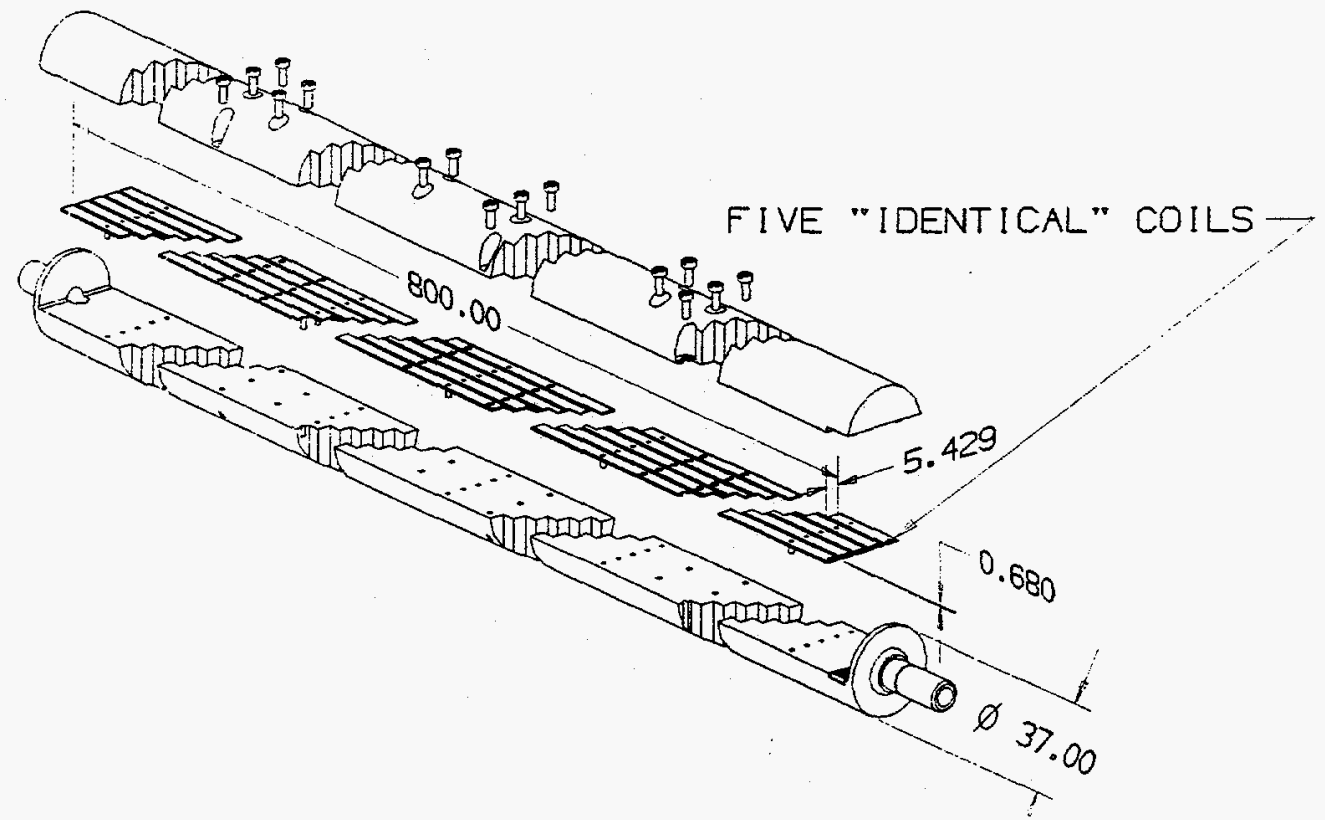

Figure 4. Quadrupole Coil Assembly.

\section{REFERENCES}

1. MWS Wire Industries, 312 Cedar Valley Drive, Westlake Village, CA 91362.

2. Metrolab Instruments SA, 110 ch. du Pont-du Centenaire, CH-1228 Geneva, Switzerland (US rep: GMW, P.O. Box 2578, Redwood City, CA 94064). 